\title{
The Coupling Mechanism between FDI and Employment Structure: A Case of Beijing
}

\author{
Liyan Liu', Hui Jia ${ }^{*}$, Shaozhong Cui² \\ ${ }^{1}$ School of Economics and Management, Beijing Institute of Petrochemical Technology, Beijing, China \\ ${ }^{2}$ School of International Economics, China Foreign Affairs University, Beijing, China \\ Email: *1244383017@qq.com
}

How to cite this paper: Liu, L.Y., Jia, H. and Cui, S.Z. (2019) The Coupling Mechanism between FDI and Employment Structure: A Case of Beijing. iBusiness, 11, 21-41.

https://doi.org/10.4236/ib.2019.113003

Received: July 26, 2019

Accepted: August 26, 2019

Published: August 29, 2019

Copyright $\odot 2019$ by author(s) and Scientific Research Publishing Inc. This work is licensed under the Creative Commons Attribution International License (CC BY 4.0).

http://creativecommons.org/licenses/by/4.0/

\begin{abstract}
As an important aspect of the industrial structure, the employment structure can better reflect the real production, true lifestyle and income distribution, and it is a key indicator to measure the development of the city. As a symbol of the openness and development of the super city, FDI has become one of the core drivers for employment structure optimization. Based on the three perspectives of sector structure, space structure and quality structure of Beijing's employment, a dual-coupling model is established to investigate the interaction mechanism and coupling effects between FDI and employment structure and to examine the role of FDI in optimizing the employment structure of Beijing. Results show that the employment structure system is better developed than FDI system, and there are coupling effects between FDI and employment structure in terms of employment sector-structure and quality-structure, while the coupling effects are not obvious in terms of space structure.
\end{abstract}

\section{Keywords}

Coupling Mechanism, FDI, Employment Structure, Coupling Effects

\section{Introduction}

As an important aspect of industrial structure, the employment structure can better reflect the real production status and lifestyle, directly affect income distribution, determine the wage level, and is an important indicator to measure the level and stage of city development. Foreign direct investment (FDI) inflows change the proportion and structure of the original production factors, affecting factor demand and thus affecting the employment structure. As one of the key indicators for the openness of an economy, FDI has become the driving force for *Corresponding author. 
a city's economic transformation, industrial structure upgrading and employment structure optimization. How to effectively use FDI to realize regional employment-structure optimization and economic transformation has become an important topic in current economic development.

The entry of FDI plays a positive role in promoting the employment level and economic growth of the host country. However, due to the heterogeneity of host country or region, and differences in human resources endowments and infrastructure, the impact of FDI's inflow on employment structure and economic development is multifaceted.

The impact of FDI on host economy's employment is basically investigated by different sample and empirical test methods, econometric models used usually established according to the Cobb-Douglas production function and its various deformations. The impact of FDI on employment level in the background of economic growth, wages and other aspects of economies is mostly based on the neoclassical growth model and the endogenous growth model.

Based on the three perspectives of employment sector-structure, employment spatial-structure and employment quality-structure of Beijing, we set up to investigate the role of FDI in optimizing the employment structure of Beijing by constructing a two-system coupling model from the coupling concept in physics to explore the dynamic interaction mechanism and interaction system between FDI and employment structure. Literature in this retrospect is quite few, and the interaction mechanism between FDI and employment structure in Beijing has unique indications for most big cities in developing countries who are expecting to upgrade their employment structure based on FDI inflow. Owing to the data obtainability, we have not further investigated the coupling effects between FDI and employment sector-structure in certain sectors, such as in high-end services sectors and high-tech sectors, and have not further examined the coupling mechanism between FDI and employment quality-structure in certain respects, as in technology innovation abilities of employees, hence could not effectively measure the exact roles FDI played in these coupling relations, which is a limitation for our research. The rest of the paper is organized as follows: 2. Literature Review; 3. Coupling Model and Data Description; 4. Results and Discussion; 5. Conclusions.

\section{Literature Review}

The current literature on FDI and the employment structure of the host economy mainly focuses on the overall employment effect of FDI, regional employment structure effect, industrial employment structure effect and skill structure effect.

For the overall employment demand, most studies claim FDI has a significant effect on overall employment demand of host economy, but whether the effect is positive or negative is quite different according to different status of host economy. Wen Huaide and Tan Jingrong (2010) pointed out that FDI had a positive effect on Chinese employment in general and had a positive effect on China's 
labor market development and human capital accumulation [1]. Research by Lipsey and Sjobolm (2001) [2] investigated various developing countries and showed that FDI expanded the demand for skilled labor and raised the average wage level of host countries. However, Borensztein et al. (1998) held the opposite view on the study of Central European countries and developing countries and believed that FDI had a significant role in promoting employment creation [3]. Yang Yang, Yu Zhuangxiong, Wang Meijin (2009) believed that FDI had a negative effect on China's employment level and had no long-term impact on wage levels [4]. Liyan Liu (2011) claimed that FDI tends to crowd out domestic capitals and reduce employment effect in the long run [5]. While David Williams's (2003) study of Latin American countries held a third view-the overall employment effect of FDI is uncertain because of the influence of FDI [5]. Yan Junlin (2007) studied the employment effects of FDI in different periods and concluded that the initial FDI employment creation effect was significantly greater than the later conclusions [6].

For the regional employment structure, current studies indicate that FDI has a significant impact on the regional employment structure, but the specific effects are of great difference according to different regions. Ding Cuicui and Guo Qingran (2014) claimed that the regional differences in the impact of FDI on employment were significant, and there was a significant crowding out effect. It is difficult to alleviate domestic employment pressure by relying on FDI [7]. Jordi Paniagua, Juan Sapena (2014) analyzed data from 161 countries and regions, pointing out that FDI inflows promoted regional labor mobility in underdeveloped countries and regions, and changed the regional employment structure of host countries, but the direction of change is still unclear [8]. Zheng Yueming and Dong Dengxin (2008) also believed that significant regional differences made the overall effect of FDI employment uncertain, and this regional disparity was closely related to the regional bias and choice of FDI [9]. Cai Wei and Wang Dewen (2004) also believed that FDI had a positive effect on increasing employment, promoting labor market development and human capital accumulation [10].

For the industrial employment structure, current studies show that FDI has a strong spillover effect on the industrial employment structure, however, the effect may be positive, negative or uncertain, which largely determined by the host economy of the research. Study of Greenstone et al. (2010) indicated that FDI directly drove China's high-tech industry growth and had a strong spillover effect on local companies [11]. Mao Risheng (2009) believed that FDI has a significant impact on manufacturing employment structure through output expansion, production efficiency and penetration rate, and the size of the impact varied with factor density and ownership structure [12]. Tang Dongbo (2011) pointed out that the inflow of FDI would help improve the domestic employment structure and increase the proportion of high-skilled workers in China [13]. However, William W. Olney (2013) held the opposite view on the employment market of developing countries and developed countries [14]. They 
believed that the inflow of FDI to the market economy and the employment of the host country with low market health is low. The structure had a negative impact, and at the same time, FDI had a significant negative impact on manufacturing employment in developed countries because it promoted the improvement of labor productivity in manufacturing. Liyan Liu (2012) pointed out that in the long run, FDI would promote the employment in second and service sector, while in the short run, FDI's spillover on employment was negative based on China's data from 1985-2008 [15].

For the aspect of employment skill structure, FDI affects the skill level of the host economy's labor force. Fu et al. (2013) pointed out that FDI inflows had a negative impact on the employment scale and wage level of low-skilled workers in foreign companies in China, and FDI inflows had not improved China's employment structure and labors' skill levels [16]; while study by Yasuyuki Todo et al. (2009) held the opposite view, pointing out that FDI had a strong positive spillover effect on highly skilled employees [17]. Similarly, Feenstra, and Hanson (1997) examined the impact of FDI on employment of blue-collar and white-collar workers in Mexico and believed that FDI has a significant positive effect on both white-collar and blue-collar employment, and FDI has promoted the labor skills and wages in Mexico [18].

The literature concerned FDI's relations with and impact on the employment structure of host economy presents the following characteristics:

1) Current research methods are mostly Cobb-dogmas production function or endogenous growth model, and research are macro-level research using national or provincial-level data.

2) Current research areas are usually focused on the overall employment demand, industrial employment structure, regional employment structure and employment skill structure of FDI, which belongs to the traditional employment structure research category.

3) Due to the differences in regions, data and model setting, there is no consistent conclusion on the employment structure effect of FDI. Therefore, it is necessary to further develop the topic from a different perspective-coupling mechanism.

\section{Coupling Model and Indicators}

\subsection{Coupling Model}

First, we construct a two-system coupling model based on the coupling concept in physics:

$$
\begin{gathered}
x_{i}=\left(X_{i}-\min X_{i}\right) /\left(\max X_{i}-\min X_{i}\right) \\
f_{i}(x)=\sum_{i=1}^{n} \alpha_{i} x_{i} \\
\sum_{i=1}^{n} \alpha_{i}=1
\end{gathered}
$$

Here $X_{i}$ is the order parameter for FDI, which indicates the $i$-th index $(i=1,2, \cdots, n)$ in FDI subsystem. $\max X_{i}$, and $\min X_{i}$ are the upper and low- 
er limits of the FDI parameter respectively. $x_{i}$ in formula (1) is the efficiency coefficient of FDI order parameter, which meets the requirement $x_{i} \subset[0,1]$; and $f(x)$ in formula (2) is the FDI synthesis order parameter. The larger the $f(x)$ value is, the higher the development level of FDI is. $\alpha_{i}$ is the weight of each order parameter.

$$
\begin{gathered}
y_{i}=\left(Y_{i}-\min Y_{i}\right) /\left(\max Y_{i}-\min Y_{i}\right) \\
f_{i}(y)=\sum_{i=1}^{n} \beta_{i} y_{i} \\
\sum_{i=1}^{n} \beta_{i}=1
\end{gathered}
$$

Here $Y_{i}$ is the order parameter for employment structure, which refers to $i$-th index $(i=1,2, \cdots, m)$ in employment structure subsystem. $\max Y_{i}$ and $\min Y_{i}$ refer to the upper and lower limits of the employment structure parameter respectively. The efficiency coefficient of order parameter for employment structure is $y_{i}$ (in parameter $\left.3, y_{i} \subset[0,1]\right)$ and $f(y)$ in formula (4) is the FDI synthesis order parameter, same with $f(x)$, the larger the value of $f(y)$, the higher the development level of employment structure. And $\beta_{i}$ is the weight of each order parameter in the subsystem of employment structure.

In the coupling coordination degree model constructed in this paper, we need to determine the weights of the order parameters of FDI and employment structure, that is, determine the values of $\alpha_{i}$ and $\beta_{i}$.

In order to avoid potential subjective influences, we apply entropy weight method (EWM) proposed by Shannon ${ }^{1}$ in this paper, and the steps of the EWM are as follows:

The first step is the dimensionlessization of the order parameters. Here $\lambda_{i j}$ is the order parameter of sample $i$, the $j$-th index of sample $i,(i=1,2, \cdots, n ; j=1$, $2, \cdots, m$ ), and the dimensionless treatment formula is:

$$
\lambda_{i t}=\frac{U_{i j}-\min \left(\lambda_{i j}\right)}{\max \lambda_{i j}-\min \left(\lambda_{i j}\right)}
$$

The second step is to calculate the proportion of the order parameter.

$$
\gamma_{i t}=\frac{\lambda_{i j}}{\sum_{i=1}^{n} \lambda_{i j}}
$$

The third step is to calculate the entropy value.

$$
s_{j}=-\sum_{i=1}^{n} \gamma_{i j} \ln \gamma_{i j}
$$

The fourth step is to calculate the information effect value of the entropy value.

$$
\rho_{j}=1-s_{j}
$$

The last step is to calculate the order parameter weights.

$$
\kappa_{j}=\frac{\rho_{j}}{\sum_{j=1}^{m} \rho_{j}}
$$

${ }^{1}$ Shannon, C.E. (1948) A Mathematical Theory of Communication. Bell System Technical Journal, 3, 3-55. 
In this paper, we would first calculate the weights of the order parameters of FDI and employment structure respectively according to the above entropy weighting method steps, that is, the values of $\alpha_{i}$ and $\beta_{i}$. And the values of $f(x)$ and $f(y)$ are calculated according to the values of $\alpha_{i}$ and $\beta_{i}$, and Equations (1) (2) (4) (5), respectively.

When $f(x)>f(y)$, it indicates that the development level of FDI is higher than the development level of employment structure, and the promotion of FDI development on employment structure is greater than the promotion of employment structure to FDI; when $f(x)<f(y)$, it indicates that the development level of FDI is lower than the development level of employment structure, and the promotion of FDI development on employment structure is less than the promotion of employment structure to FDI.

Based on parameter (2) and (4), we first get the coupling function Cbetween FDI and employment structure:

$$
C\left(f_{i}(x), f_{i}(y)\right)=2\left[\sqrt{f_{i}(x) \times f_{i}(y)} /\left(f_{i}(x)+f_{i}(y)\right)\right]
$$

If $C\left(f_{i}(x), f_{i}(y)\right)=0$, it means that there is no correlation between the two systems, and the coupling relationship between the two systems is extremely poor; if $0<C \leq 0.3$, it indicates that the development of $X$ is lagging, and $Y$ system is the major development subsystem, and the two systems are at low level of coupling; if $0.3<C\left(f_{i}(x), f_{i}(y)\right)<0.5$, it indicates that the development of system $Y$ is lagging, and the $\mathrm{X}$ system is the major development system, and the two systems are in a moderate level of coupling. If $0.5 \leq C\left(f_{i}(x), f_{i}(y)\right) \leq 0.8$, it indicates the benign coupling between $X$ system and $Y$ system; if $0.8 \leq C\left(f_{i}(x), f_{i}(y)\right)<1$, it refers that system $X$ interacts with the system $Y$, and the two are at a high level of coupling. And when $C\left(f_{i}(x), f_{i}(y)\right)=1$, it shows that system $X$ interacts with the $Y$ system in an orderly manner, and the coupling degree is the highest.

\subsection{Coupling Coordination Degree and Evaluation Method}

The closer the coupling function value $\left(C\left(f_{i}(x), f_{i}(y)\right)\right)$ to 1 , the higher the degree of coupling between the two systems. However, when the development level of the two systems are both very low and the development level is kind of equivalent, the value of $C\left(f_{i}(x), f_{i}(y)\right)$ will also be close to 1 , resulting in a high level of "pseudo-coordination" coupling phenomenon. Therefore, we need to calculate the coupling coordination degree function $D$ (Equation (13) is based on Equation (12) to simultaneously reflect the coupling degree between the two and the true development level of both. Based on the calculation results of each system index, we will get the coupling degree between the systems:

$$
D\left(f_{i}(x), f_{i}(y)\right)=\sqrt{C \times T}, T=A f_{i}(x)+B f_{i}(y)
$$

Here $A$ is the role of FDI in the coordination of employment structure development, and $B$ is the role of employment structure in the development of FDI. 
According to the actual situation of industrial operation in China ${ }^{2}$ and Beijing, a and $\mathrm{b}$ are valued as $a=0.6$ and $b=0.4$ in this study ${ }^{3}$.

The value of $D\left(f_{i}(x), f_{i}(y)\right)$ is the coupling coordination degree between the two systems. When $D\left(f_{i}(x), f_{i}(y)\right) \in[0,0.01]$, there is no coupling relation between the two systems; when $D\left(f_{i}(x), f_{i}(y)\right) \in(0.01,0.29]$, it indicates that the development of the two is at a low level. And the low-level coupling phase can be further divided into three categories: extreme inharmonious recession, severe inharmonious recession, and moderate inharmonious recession (see Table 1). During low-level coupling phase, the influence between the elements of the two systems is at low level, and the two systems are basically uncoordinated and unbalanced.

When $D\left(f_{i}(x), f_{i}(y)\right) \in(0.3,0.60]$, the mutual influence between the elements in two systems is not obvious, the relation between the two systems is basically uncoordinated, and the systems are in the moderate coupling phase, which can be further divided into three sub-phases: mild inharmonious recession, near-harmonious recession, and near-coordinated development; when $D\left(f_{i}(x), f_{i}(y)\right) \in(0.60,0.80]$, there is a certain mutual influence between the elements of the two systems, and the systems are in the benign coupling phase. When $D\left(f_{i}(x), f_{i}(y)\right) \in(0.8,0.99]$, the interaction between the elements of the two systems is obvious, the two systems develop harmoniously, and are in the high-level coupling stage. When $D\left(f_{i}(x), f_{i}(y)\right) \in(0.99,1.00]$, the development trajectory of the two systems is exactly the same, and the two systems are in a fully coupling state (see Table 1).

\subsection{Coupling Indicators and Data Description}

We aim to discuss the coupling effect between FDI and employment structure in Beijing in terms of employment in sectors, employment quality and spatial distribution, based on which we selected the indicators.

In the coupling mechanism between FDI and employment sector-structure, for the indicator selection of the FDI system, we divided all sectors with FDI inflows in Beijing's three industries into basic sector, general service sector, business services sector, high-tech services sector, real estate sector and the sector of others, so as to feature the characteristics of FDI inflow and the structure of FDI inflow (in Table 2). The basic sector in FDI system includes agriculture, forestry, animal husbandry, fishery, manufacturing, and construction. The general service sector in FDI system includes wholesale and retail, accommodation and catering, and the business services sector is leasing and business services. The high-tech service sector includes information transmission, computer services and software.

${ }^{2}$ Detailed information could be found in the literature review part.

${ }^{3}$ From the previous studies and the actual situation in China and Beijing, FDI has played an recognizable role in job creation, which has been showed by a lot of literature in this field, while employment's role on FDI attraction is not as significant as FDI on employment. One or two of the literatures described the causal relations can be Liyan Liu (2011) and Liyan Liu (2012). 
Table 1. Evaluation system of coupling coordinated degree.

\begin{tabular}{ccc}
\hline Correlation & Type & Coupling phase \\
\hline$[0.00-0.01]$ & uncoupling & uncoupling phase \\
$(0.01-0.10]$ & extreme inharmonious recession & \\
$(0.10-0.20]$ & severe inharmonious recession & low level coupling \\
$(0.20-0.30]$ & moderate inharmonious recession & \\
$(0.30-0.40]$ & mild inharmonious recession & \\
$(0.40-0.50]$ & near-inharmonious recession & moderate coupling \\
$(0.50-0.60]$ & near-coordinated development & \\
$(0.60-0.70]$ & primary coordinated development & benign coupling \\
$(0.70-0.80]$ & moderate coordinated development & \\
$(0.80-0.90]$ & good coordinated development & high level coupling \\
$(0.90-0.99]$ & quality coordinated development & full coupling \\
$(0.99-1]$ & full coupling & \\
\hline
\end{tabular}

Table 2. Indicators in FDI system and employment sector-structure system.

\begin{tabular}{|c|c|c|}
\hline Name & Primary indicator & Secondary indicators \\
\hline \multirow{12}{*}{$\begin{array}{c}\text { FDI } \\
\text { system-sector }\end{array}$} & \multirow{6}{*}{ FDI sector inflow } & basic sector FDI inflow $\left(S_{1}\right)$ \\
\hline & & general service sector FDI inflow $\left(S_{2}\right)$ \\
\hline & & business services sector FDI inflow $\left(S_{3}\right)$ \\
\hline & & high-tech services sector FDI inflow $\left(S_{4}\right)$ \\
\hline & & real estate sector FDI inflow $\left(S_{5}\right)$ \\
\hline & & the sector of others FDI inflow $\left(S_{6}\right)$ \\
\hline & \multirow{6}{*}{$\begin{array}{l}\text { FDI sector inflow } \\
\text { structure }\end{array}$} & basic sector ratio $\left(S_{1}\right)$ \\
\hline & & general service sector ratio $\left(S_{2}\right)$ \\
\hline & & business services sector ratio $\left(S_{3}\right)$ \\
\hline & & high-tech services sector ratio $\left(S_{4}\right)$ \\
\hline & & real estate sector ratio $\left(S_{5}\right)$ \\
\hline & & the sector of others ratio $\left(S_{6}\right)$ \\
\hline \multirow{12}{*}{$\begin{array}{l}\text { employment } \\
\text { sector-structure } \\
\text { system }\end{array}$} & \multirow{6}{*}{ sector employment } & basic sector employment $\left(G_{1}\right)$ \\
\hline & & general service sector employment $\left(G_{2}\right)$ \\
\hline & & business service sector employment $\left(G_{3}\right)$ \\
\hline & & high-end service sector employment $\left(G_{4}\right)$ \\
\hline & & real estate sector employment $\left(G_{5}\right)$ \\
\hline & & other services sector employment $\left(G_{6}\right)$ \\
\hline & \multirow{6}{*}{ sector average wage } & average wage in basic sector $\left(G_{7}\right)$ \\
\hline & & average wage in general service sector $\left(G_{8}\right)$ \\
\hline & & average wage in business service sector $\left(G_{9}\right)$ \\
\hline & & average wage in high-end service sector $\left(G_{10}\right)$ \\
\hline & & average wage in real estate sector $\left(G_{11}\right)$ \\
\hline & & average wage in other services sector employment $\left(G_{12}\right)$ \\
\hline
\end{tabular}


Since factors concerned with employment are focused on number of employees and wage of employees. Therefore, employees, employee distribution and wages are the most important aspects to feature employment structure. And in this paper, employee's sector distribution is used to feature the sector-structure of employment. The indicators in employment system are divided into two primary indicators: sector employment and sector wage. Secondary indicators include employment in basic sector, general service sector, business service sector, high-end service sector, real estate sector and sector of other services. The sector wage indicators include the average wage of the basic sector, the average wage of the general service sector, the business service sector, the real estate sector and sector of other services. The basic sector in employment system includes agriculture, forestry, animal husbandry, fisheries, mining, manufacturing, electricity, heat, gas and water production and supply, construction; general service sector includes wholesale and retail, transportation, warehousing and postal services, accommodation and catering; business services sector includes leasing and business services; high-end services sector includes information transmission, software and information technology services, finance, scientific research and technology services, education ${ }^{4}$; and sector for other services includes water, environment and public Facilities management, residential services, repairs and other services, health and social work, culture, sports and entertainment, public administration, social security and social organization. See Table 2 for details.

For the coupling mechanism of FDI and employment quality-structure in Beijing, the indicators for FDI system includes two primary indicators: FDI inflow quality characteristic and FDI inflow quality structure. FDI inflow quality characteristic includes four secondary indicators as actual usage of FDI in Beijing, actual usage of FDI in manufacturing sector, actual usage of FDI in service sector, actual usage of FDI in high-tech sector. FDI inflow quality structure includes three ratios to feature the quality structure of FDI inflows (see Table 3). Here we use FDI distribution sectors to feature the characteristics and quality of FDI. The larger ratio of FDI in high-tech services, the better the quality of FDI.

The quality-structure of employment in Beijing is divided into three aspects: personnel quality structure, wage structure and technical level. Secondary indicators are the employment ratio of manufacturing sector, the employment ratio of service sector, the employment ratio of high-end service sector; the average wage of the manufacturing sector, service sector and the high-end service sector; the number of scientific and technological personnel, and the number of patent applications (see Table 3). Here we use employment distribution sectors and the average wage of particular sectors to feature the quality of employment. The more people, the larger ratio of employees and the higher average wage in high-end services, the better the employment quality structure.

${ }^{4}$ Here the high-end service sector is defined by the intensity of knowledge, science and technology, so the information transmission, software and information technology services, finance, scientific research and technology services, and education sectors are included in the high-end service sector. 
Table 3. Indicators in FDI system and employment quality-structure system.

\begin{tabular}{|c|c|c|}
\hline Name & Primary indicator & Secondary indicators \\
\hline \multirow{7}{*}{$\begin{array}{l}\text { FDI system-quality } \\
\text { structure }\end{array}$} & \multirow{4}{*}{$\begin{array}{l}\text { FDI inflow quality } \\
\text { characteristics }\end{array}$} & actual usage of FDI in Beijing $\left(Q_{1}\right)$ \\
\hline & & actual usage of FDI in manufacturing sector $\left(Q_{2}\right)$ \\
\hline & & actual usage of FDI in service sector $\left(Q_{3}\right)$ \\
\hline & & actual usage of FDI in high-tech sector $\left(Q_{4}\right)$ \\
\hline & \multirow{3}{*}{$\begin{array}{l}\text { FDI inflow quality } \\
\text { structure }\end{array}$} & ratio of actual usage of FDI in manufacturing sector $\left(Q_{5}\right)$ \\
\hline & & ratio of actual usage of FDI in service sector $\left(Q_{6}\right)$ \\
\hline & & ratio of actual usage of FDI in high-tech sector $\left(Q_{7}\right)$ \\
\hline \multirow{7}{*}{$\begin{array}{c}\text { employment } \\
\text { quality-structure } \\
\text { system }\end{array}$} & \multirow{3}{*}{$\begin{array}{l}\text { personnel quality } \\
\text { structure }\end{array}$} & employment ratio of manufacturing sector $\left(H_{1}\right)$ \\
\hline & & employment ratio of service sector $\left(H_{2}\right)$ \\
\hline & & employment ratio of high-end service sector $\left(H_{3}\right)$ \\
\hline & \multirow{3}{*}{ wage structure } & average wage in manufacturing sector $\left(H_{4}\right)$ \\
\hline & & average wage in service sector $\left(H_{5}\right)$ \\
\hline & & average wage in high-end service sector $\left(H_{6}\right)$ \\
\hline & technical level & $\begin{array}{l}\text { scientific and technological personnel }\left(H_{7}\right) \\
\text { patent applications }\left(H_{8}\right)\end{array}$ \\
\hline
\end{tabular}

Here we use the districts distribution of FDI, employment and average wage to feature the FDI and employment space-structure. According to the spatial distribution of FDI and Beijing's employment structure, the 16 districts and counties in Beijing are divided into four levels: central urban area, urban area, suburban area and remote suburb. The central city area includes Dongcheng and Xicheng districts; the urban area includes Chaoyang, Fengtai, Shijingshan and Haidian districs; the suburban area includes six districts as Tongzhou, Daxing, Changping, Shunyi, Mentougou and Fangshan; the outer suburbs includes Miyun, Yanqing, Pinggu and Huairou districts.

The FDI inflow spatial structure indicators include the actual usage of FDI in Beijing, the actual usage of FDI in the central city, the actual usage of FDI in urban area, the actual usage of FDI in the suburban areas, the actual usage of FDI in the outer suburb area, and the ratio of actual usage of FDI in each area (see Table 4). The indicators for spatial structure of employment includes three primary indicators as space employment, spatial structure and average wage, and fourteen secondary indicators as the total employment in Beijing; the employment in the central city area, urban area, near suburban area and outer suburb areas; the ratio of employment in central city area, urban area, near suburban area and outer suburb areas; the average wage of urban employees in Beijing, and the average wage of urban employees in central city area, urban area, near suburban area and outer suburb (see Table 4 for details).

The original data of the research is from the Beijing Statistical Yearbook (2007-2018), Beijing Regional Statistical Yearbook (2007-2018) and the China 
Table 4. Indicators in FDI system and employment space-structure system.

\begin{tabular}{|c|c|c|}
\hline Name & Primary indicator & Secondary indicators \\
\hline \multirow{9}{*}{$\begin{array}{c}\text { FDI } \\
\text { system-space } \\
\text { structure }\end{array}$} & & actual usage of FDI in Beijing $\left(D_{1}\right)$ \\
\hline & & actual usage of FDI in the central city $\left(D_{2}\right)$ \\
\hline & $\begin{array}{l}\text { space distribution of } \\
\text { FDI inflow }\end{array}$ & actual usage of FDI in urban area $\left(D_{3}\right)$ \\
\hline & & actual usage of FDI in the suburban areas $\left(D_{4}\right)$ \\
\hline & & actual usage of FDI in the outer suburb area $\left(\left(D_{5}\right)\right.$ \\
\hline & & ration of actual usage of FDI in the central city $\left(D_{6}\right)$ \\
\hline & space structure of FDI & actual usage of FDI in urban area $\left(D_{7}\right)$ \\
\hline & inflow & actual usage of FDI in the suburban areas $\left(D_{8}\right)$ \\
\hline & & actual usage of FDI in the outer suburb area $\left(D_{9}\right)$ \\
\hline \multirow{14}{*}{$\begin{array}{c}\text { employment } \\
\text { space-structure } \\
\text { system }\end{array}$} & & total employment in Beijing $\left(Z_{1}\right)$ \\
\hline & & employment in the central city area $\left(Z_{2}\right)$ \\
\hline & space employment & employment in the urban area $\left(Z_{3}\right)$ \\
\hline & & employment in the near suburban area $\left(Z_{4}\right)$ \\
\hline & & employment in the outer suburb area $\left(Z_{5}\right)$ \\
\hline & & ratio of employment in the central city area $\left(Z_{6}\right)$ \\
\hline & \multirow{3}{*}{ spatial structure } & ratio of employment in the urban area $\left(Z_{7}\right)$ \\
\hline & & ratio of employment in the near suburban area $\left(Z_{8}\right)$ \\
\hline & & ratio of employment in the outer suburb area $\left(Z_{9}\right)$ \\
\hline & \multirow[t]{5}{*}{ average wage } & average wage in Beijing $\left(Z_{10}\right)$ \\
\hline & & average wage in central city area $\left(Z_{11}\right)$ \\
\hline & & average wage in urban area $\left(Z_{12}\right)$ \\
\hline & & average wage in near suburban area $\left(Z_{13}\right)$ \\
\hline & & average wage in outer suburb $\left(Z_{14}\right)$ \\
\hline
\end{tabular}

City Statistical Yearbook (2007-2018). All the data are converted into RMB and de-inflated according to the exchange rate and inflation index of the year. The treated data is dimensionless according to the range method shown in formula (1) and (4), and the minimum value-0 value data-is assigned to the value of 0.01 , and the sum of data characteristics are shown in Tables 5-7 below.

From Table 5 we can find that the standard deviation of FDI and Beijing employment industry structure data is basically between 0.27 and 0.42 . The data distribution interval is reasonable and concentrated. In terms of the average value, the data value interval is reasonable and there is no abnormal value in the data set.

It can be seen from Table 6 that the standard deviation of FDI and Beijing employment quality structure data is basically between 0.27 and 0.49 . The data distribution interval is reasonable and concentrated. In terms of the average value, the data value interval is reasonable and there is no abnormal value. 
Table 5. Sum of data in FDI system and employment sector-structure system.

\begin{tabular}{|c|c|c|c|c|c|}
\hline Variable & Obs & Mean & Std. Dev. & Min & Max \\
\hline$s_{1}$ & 10 & 0.3473 & 0.2729 & 0.0100 & 1.0000 \\
\hline$s_{2}$ & 10 & 0.2052 & 0.3001 & 0.0100 & 1.0000 \\
\hline$s_{3}$ & 10 & 0.4477 & 0.2813 & 0.0100 & 1.0000 \\
\hline$s_{4}$ & 10 & 0.1392 & 0.3027 & 0.0100 & 1.0000 \\
\hline$s_{5}$ & 10 & 0.4342 & 0.2743 & 0.0100 & 1.0000 \\
\hline$s_{6}$ & 10 & 0.2554 & 0.3138 & 0.0100 & 1.0000 \\
\hline$s_{7}$ & 10 & 0.3749 & 0.2703 & 0.0100 & 1.0000 \\
\hline$s_{8}$ & 10 & 0.2071 & 0.2972 & 0.0009 & 1.0000 \\
\hline$s_{9}$ & 10 & 0.5006 & 0.3459 & 0.0100 & 1.0000 \\
\hline$s_{10}$ & 10 & 0.2709 & 0.2683 & 0.0100 & 1.0000 \\
\hline$s_{11}$ & 10 & 0.5077 & 0.2938 & 0.0100 & 1.0000 \\
\hline$s_{12}$ & 10 & 0.2448 & 0.2904 & 0.0100 & 1.0000 \\
\hline$g_{1}$ & 10 & 0.4667 & 0.3896 & 0.0100 & 1.0000 \\
\hline$g_{2}$ & 10 & 0.6186 & 0.4162 & 0.0100 & 1.0000 \\
\hline$g_{3}$ & 10 & 0.3511 & 0.3714 & 0.0100 & 1.0000 \\
\hline$g_{4}$ & 10 & 0.4721 & 0.3407 & 0.0100 & 1.0000 \\
\hline$g_{5}$ & 10 & 0.4979 & 0.3652 & 0.0100 & 1.0000 \\
\hline$g_{6}$ & 10 & 0.5385 & 0.3419 & 0.0100 & 1.0000 \\
\hline$g_{7}$ & 10 & 0.4771 & 0.3416 & 0.0100 & 1.0000 \\
\hline$g_{8}$ & 10 & 0.4776 & 0.3522 & 0.0100 & 1.0000 \\
\hline$g_{9}$ & 10 & 0.5280 & 0.3546 & 0.0100 & 1.0000 \\
\hline$g_{10}$ & 10 & 0.4780 & 0.3378 & 0.0100 & 1.0000 \\
\hline$g_{11}$ & 10 & 0.4949 & 0.3647 & 0.0100 & 1.0000 \\
\hline$g_{12}$ & 10 & 0.4129 & 0.3313 & 0.0100 & 1.0000 \\
\hline
\end{tabular}

Table 6. Sum of data in FDI system and employment quality-structure system.

\begin{tabular}{cccccc}
\hline Variable & Obs & Mean & Std. Dev. & Min & Max \\
\hline$q_{1}$ & 10 & 0.2061 & 0.3073 & 0.0100 & 1.0000 \\
$q_{2}$ & 10 & 0.3402 & 0.2730 & 0.0100 & 1.0000 \\
$q_{3}$ & 10 & 0.2343 & 0.3008 & 0.0100 & 1.0000 \\
$q_{4}$ & 10 & 0.1392 & 0.3027 & 0.0100 & 1.0000 \\
$q_{5}$ & 10 & 0.3663 & 0.2711 & 0.0100 & 1.0000 \\
$q_{6}$ & 10 & 0.6526 & 0.3010 & 0.0100 & 1.0000 \\
$q_{7}$ & 10 & 0.2709 & 0.2683 & 0.0100 & 1.0000 \\
$h_{1}$ & 10 & 0.5730 & 0.3415 & 0.0100 & 1.0000 \\
$h_{2}$ & 10 & 0.5167 & 0.4940 & 0.0100 & 1.0000 \\
$h_{3}$ & 10 & 0.4451 & 0.4709 & 0.0001 & 1.0000 \\
$h_{4}$ & 10 & 0.4625 & 0.3409 & 0.0100 & 1.0000 \\
$h_{5}$ & 10 & 0.4703 & 0.3415 & 0.0100 & 1.0000 \\
$h_{6}$ & 10 & 0.4780 & 0.3378 & 0.0100 & 1.0000 \\
$h_{7}$ & 10 & 0.4903 & 0.3121 & 0.0100 & 1.0000 \\
$h_{8}$ & 10 & 0.4696 & 0.3727 & 0.0100 & 1.0000 \\
\hline
\end{tabular}


Table 7. Sum of data in FDI system and employment quality-structure system.

\begin{tabular}{|c|c|c|c|c|c|}
\hline Variable & Obs & Mean & Std. Dev. & Min & Max \\
\hline$d_{1}$ & 12 & 0.1942 & 0.2830 & 0.0080 & 1.0000 \\
\hline$d_{2}$ & 12 & 0.1053 & 0.2823 & 0.0034 & 1.0000 \\
\hline$d_{3}$ & 12 & 0.3275 & 0.3656 & 0.0100 & 1.0000 \\
\hline$d_{4}$ & 12 & 0.2575 & 0.3056 & 0.0057 & 1.0000 \\
\hline$d_{5}$ & 12 & 0.2943 & 0.2469 & 0.0100 & 1.0000 \\
\hline$d_{6}$ & 12 & 0.2485 & 0.2594 & 0.0100 & 1.0000 \\
\hline$d_{7}$ & 12 & 0.5583 & 0.2312 & 0.0100 & 1.0000 \\
\hline$d_{8}$ & 12 & 0.3617 & 0.3428 & 0.0100 & 1.0000 \\
\hline$d_{9}$ & 12 & 0.3434 & 0.2700 & 0.0100 & 1.0000 \\
\hline$Z_{1}$ & 12 & 0.6068 & 0.3374 & 0.0100 & 1.0000 \\
\hline$Z_{2}$ & 12 & 0.4776 & 0.3665 & 0.0061 & 1.0000 \\
\hline$z_{3}$ & 12 & 0.6130 & 0.3417 & 0.0100 & 1.0000 \\
\hline$Z_{4}$ & 12 & 0.6546 & 0.3349 & 0.0100 & 1.0000 \\
\hline$Z_{5}$ & 12 & 0.6021 & 0.3316 & 0.0100 & 1.0000 \\
\hline$z_{6}$ & 12 & 0.3489 & 0.2975 & 0.0100 & 1.0000 \\
\hline$Z_{7}$ & 12 & 0.4779 & 0.2977 & 0.0013 & 1.0000 \\
\hline$z_{8}$ & 12 & 0.7124 & 0.2935 & 0.0100 & 1.0000 \\
\hline$Z_{9}$ & 12 & 0.5342 & 0.2697 & 0.0100 & 1.0000 \\
\hline
\end{tabular}

It can be seen from Table 7 that the standard deviation of FDI and Beijing employment space structure data is basically between $0.23-0.37$, and the data distribution is more concentrated than that of FDI and Beijing employment industry structure data and that of FDI and Beijing employment quality structure data. In terms of the mean value, the data value interval is reasonable, and there is no abnormal value.

\section{Results and Discussion}

According to the two-system coupling model and the entropy weighting method model, the coupling degree $C$ between the FDI and the employment sector-structure, quality-structure and spatial-structure of Beijing employment is obtained. Due to the possible "pseudo-coordination" phenomenon of the coupling degree $C$, and in order to reflect the true coupling degree and the true development level of the two systems, the coupling degree $C$ is adjusted according to Equation (13), and the adjusted coupling coordinated degree function $D$ is calculated. The order parameter of $X$ and $Y$, coupling degree $C$ and the coupling coordinated degree $D$ of FDI and Beijing employment sector-structure is shown in Table 8.

The order parameter series of FDI and employment listed in Table 8 indicates that from year 2010 to 2017, employment structure system over-performed FDI 
Table 8. Coupling results between FDI and employment sector-structure.

\begin{tabular}{cccccccc}
\hline Year & $S(x)$ & $G(y)$ & $C$ & $D$ & Type & Coupling phase \\
\hline 2008 & 0.4080 & 0.0280 & 0.4901 & 0.3542 & mild inharmonious recession & moderate coupling \\
2009 & 0.3854 & 0.0722 & 0.7291 & 0.4355 & near-inharmonious recession & moderate coupling \\
2010 & 0.3916 & 0.1637 & 0.9119 & 0.5234 & near-coordinated development & moderate coupling \\
2011 & 0.3405 & 0.3520 & 0.9999 & 0.5874 & near-coordinated development & moderate coupling \\
2012 & 0.3171 & 0.4920 & 0.9764 & 0.6147 & primary coordinated development & benign coupling \\
2013 & 0.3935 & 0.5935 & 0.9793 & 0.6810 & primary coordinated development & benign coupling \\
2014 & 0.4518 & 0.6686 & 0.9811 & 0.7269 & moderate coordinated development & benign coupling \\
2015 & 0.2243 & 0.7511 & 0.8416 & 0.6051 & primary coordinated development & benign coupling \\
2016 & 0.2871 & 0.8281 & 0.8745 & 0.6636 & primary coordinated development & benign coupling \\
2017 & 0.4047 & 0.9241 & 0.9204 & 0.7508 & moderate coordinated development & benign coupling
\end{tabular}

system $(G(y)>S(x))$. And the FDI system development is still at the initial stage of development (in 2017 the order quantity is 0.4047 ), and the industry structure of FDI inflow is not perfect and needs to be further improved.

The coupling coordinated degree $D$ is significantly lower than the coupling degree $C$, indicating that there is a pseudo-coordination phenomenon, that is, the FDI system is not consistent with the employment structure system adjustment, and the employment structure system develops relatively faster. However, the interaction between the two systems gradually increased from year 2008 to year 2017. The adjusted coupling coordination degree increased from 0.3542 in 2008 to 0.7508 in 2017, which means that the employment creation effect of FDI in Beijing is increasing year by year, and the mutual causal effect or impact between FDI and employment is gradually increasing.

Beijing's employment structure system and FDI system have increasingly improved, but the two are still in a benign coupling phase and have not reached the high-level coupling phase Therefore, it is necessary to further guide the FDI inflow, and improve FDI's job creation effect and spillover effect on sector employment.

From the perspective of the FDI and employment structure system in Beijing (Table 9), the development of employment quality-structure is more advanced than the FDI quality structure $(H(y)>Q(x))$. After adjustment, the true coupling coordinated degree $D$ is lower than the coupling degree $C$, indicating that there is a pseudo-coordination phenomenon. That is, the development of the two systems have not reached the optimal state, and the quality structure of the employment and FDI inflow still need to be further promoted.

The interaction between the two systems is gradually increasing in the past ten years, and Beijing's employment quality-structure has been well developed, largely reflected by the employment increase in the service sectors, the development of the high-end service sector, and the raise of the average wage in the service industry, especially in the high-end service sectors. 
Table 9. Coupling results between FDI and employment quality-structure.

\begin{tabular}{cccccccc}
\hline Year & $Q(x)$ & $H(y)$ & $C$ & $D$ & Type & Coupling phase \\
\hline 2008 & 0.4180 & 0.3129 & 0.9896 & 0.6100 & primary coordinated development & benign coupling \\
2009 & 0.3094 & 0.2082 & 0.9807 & 0.5136 & near-coordinated development & moderate coupling \\
2010 & 0.3116 & 0.3875 & 0.9941 & 0.5830 & near-coordinated development & moderate coupling \\
2011 & 0.2864 & 0.3146 & 0.9989 & 0.5453 & near-coordinated development & moderate coupling \\
2012 & 0.3274 & 0.5504 & 0.9672 & 0.6348 & primary coordinated development & benign coupling \\
2013 & 0.3280 & 0.4446 & 0.9885 & 0.6085 & primary coordinated development & benign coupling \\
2014 & 0.3211 & 0.6797 & 0.9336 & 0.6586 & primary coordinated development & benign coupling \\
2015 & 0.3313 & 0.5484 & 0.9691 & 0.6366 & primary coordinated development & benign coupling \\
2016 & 0.3695 & 0.7834 & 0.9333 & 0.7067 & moderate coordinated development & benign coupling \\
2017 & 0.6372 & 0.6754 & 0.9996 & 0.8076 & good coordinated development & high level coupling \\
\hline
\end{tabular}

At the same time, the number of scientific and technological personnel has grown rapidly, and patent applications increased. However, the interaction effect between the two systems still needs to be further improved, that is, the knowledge spillover effect of FDI needs to be further improved.

The two system parameters in Table 10 shown that the order parameter value of employment spatial-structure system is higher than that of the FDI system, indicating that the employment system development is relatively more mature, and the FDI system is relatively backward. The value of coupling degree $C$ is significantly higher than the adjusted $D$ value, indicating that there is a pseudo-coordination phenomenon between the two systems. Therefore, the development of the two systems is not at heir optimal state, and both two systems need to be improved. FDI's spatial distribution rationality and employment effect still need to be further enhanced.

Since there are 16 districts in Beijing, whose geographical location, resources endowment and economic development patterns are quite different. In order to further determine the uncoordinated factors between systems of FDI and employment space distribution, based on the geographical location of each district, we divide these sixteen districts into four geographic areas as central city area, urban area, suburban area and outer suburbs.

As shown in Table 11, the order parameter value of employment structure system $\left(Z_{1}(y)\right)$ is higher than that of the FDI system $\left(D_{1}(x)\right)$, indicating that the employment system development is relatively more mature, and the FDI system is relatively backward. The coupling degree $C$ is obviously higher than the adjusted one $D$, indicating that there is an obvious pseudo-coordination phenomenon between the two systems; therefore, the development of the two systems themselves is not perfect and needs to be further improved.

The systems of FDI and employment structure in the central city area have been in a moderate coupling phase from year 2006 to 2014. There is a sudden drop off in year 2015, and a quick recovery in year 2016. The decrease in the 
Table 10. Coupling results between FDI and employment space-structure (Beijing in total).

\begin{tabular}{cccccccc}
\hline Year & $D(x)$ & $Z(y)$ & $C$ & $D$ & Type & Coupling phase \\
\hline 2006 & 0.2284 & 0.1248 & 0.9560 & 0.4227 & near-inharmonious recession & moderate coupling \\
2007 & 0.2337 & 0.1557 & 0.9798 & 0.4454 & near-inharmonious recession & moderate coupling \\
2008 & 0.2154 & 0.3021 & 0.9859 & 0.4966 & near-inharmonious recession & moderate coupling \\
2009 & 0.2416 & 0.3712 & 0.9774 & 0.5356 & near-coordinated development & moderate coupling \\
2010 & 0.2449 & 0.4549 & 0.9539 & 0.5601 & near-coordinated development & moderate coupling \\
2011 & 0.2800 & 0.5310 & 0.9509 & 0.6014 & primary coordinated development & benign coupling \\
2012 & 0.4059 & 0.5950 & 0.9820 & 0.6877 & primary coordinated development & benign coupling \\
2013 & 0.5341 & 0.6464 & 0.9955 & 0.7592 & moderate coordinated development & benign coupling \\
2014 & 0.3905 & 0.7223 & 0.9545 & 0.7067 & moderate coordinated development & benign coupling \\
2015 & 0.3338 & 0.7781 & 0.9167 & 0.6848 & primary coordinated development & benign coupling \\
2016 & 0.4525 & 0.7423 & 0.9701 & 0.7426 & moderate coordinated development & benign coupling \\
2017 & 0.4949 & 0.7857 & 0.9739 & 0.7715 & moderate coordinated development & benign coupling \\
\hline
\end{tabular}

Table 11. Coupling results between FDI and employment space-structure (Central City Area).

\begin{tabular}{cccccccc}
\hline Year & $D_{I}(x)$ & $Z_{I}(y)$ & $C$ & $D$ & Type & Coupling phase \\
\hline 2006 & 0.1933 & 0.3388 & 0.9619 & 0.4919 & near-inharmonious recession & moderate coupling \\
2007 & 0.1667 & 0.3518 & 0.9341 & 0.4742 & near-inharmonious recession & moderate coupling \\
2008 & 0.3191 & 0.2027 & 0.9748 & 0.5154 & near-coordinated development & moderate coupling \\
2009 & 0.3846 & 0.2119 & 0.9571 & 0.5496 & near-coordinated development & moderate coupling \\
2010 & 0.2725 & 0.2825 & 0.9998 & 0.5258 & near-coordinated development & moderate coupling \\
2011 & 0.2113 & 0.3831 & 0.9573 & 0.5178 & near-coordinated development & moderate coupling \\
2012 & 0.2094 & 0.4952 & 0.9140 & 0.5439 & near-coordinated development & moderate coupling \\
2013 & 0.1661 & 0.5312 & 0.8520 & 0.5157 & near-coordinated development & moderate coupling \\
2014 & 0.0906 & 0.5979 & 0.6761 & 0.4455 & near-inharmonious recession & moderate coupling \\
2015 & 0.0102 & 0.6439 & 0.2483 & 0.2559 & moderate coordinated development low level coupling \\
2016 & 0.0252 & 0.5055 & 0.4256 & 0.3041 & mild coordinated development & moderate coupling \\
2017 & 1.0000 & 0.5451 & 0.9557 & 0.8842 & good coordinated development & high level coupling \\
\hline
\end{tabular}

order parameter of FDI system in year 2015, from 0.0906 in 14 down to 0.0102 in 2015 , seems to be the major cause for the sudden drop of value $D$. In addition, the FDI system itself is not stable; therefore, it is necessary to further guide the FDI inflow in the central city area and take measures to improve the quality of FDI.

The values of the two system parameters $D_{2}(x)$ and $Z_{2}(y)$ (Table 12) indicate that the employment system is more developed than the FDI system $\left(Z_{2}(y)>\right.$ $D_{2}(x)$ ), and there is a coupling interaction between the two systems. Since he 
Table 12. Coupling results between FDI and employment space-structure (Urban Area).

\begin{tabular}{cccccccc}
\hline Year & $D_{2}(x)$ & $Z_{2}(y)$ & $C$ & $D$ & Type & Coupling phase \\
\hline 2006 & 0.2938 & 0.0100 & 0.3568 & 0.2536 & moderate inharmonious recession & low level coupling \\
2007 & 0.3831 & 0.0475 & 0.6265 & 0.3949 & moderate inharmonious recession & moderate coupling \\
2008 & 0.2803 & 0.2923 & 0.9998 & 0.5339 & near-coordinated development & moderate coupling \\
2009 & 0.3435 & 0.3846 & 0.9984 & 0.5995 & near-coordinated development & moderate coupling \\
2010 & 0.3737 & 0.3965 & 0.9996 & 0.6186 & primary coordinated development & benign coupling \\
2011 & 0.3406 & 0.4463 & 0.9909 & 0.6159 & primary coordinated development & benign coupling \\
2012 & 0.4056 & 0.5333 & 0.9907 & 0.6726 & primary coordinated development & benign coupling \\
2013 & 0.4272 & 0.6422 & 0.9796 & 0.7090 & moderate coordinated development & benign coupling \\
2014 & 0.5273 & 0.6917 & 0.9909 & 0.7666 & moderate coordinated development & benign coupling \\
2015 & 1.0000 & 0.8139 & 0.9947 & 0.9595 & quality coordinated development & high level coupling \\
2016 & 0.8481 & 0.8932 & 0.9997 & 0.9305 & quality coordinated development & high level coupling \\
2017 & 0.3408 & 0.9977 & 0.3408 & 0.5831 & near-coordinated development & moderate coupling \\
\hline
\end{tabular}

value of coupling degree $C$ is not much different from the true adjusted value $D$, especially in 2015-2016, when the $C$ and $D$ values are all above 0.9 , there is no obvious pseudo coordination phenomenon in the four urban districts of as Chaoyang, Fengtai, Shijingshan and Haidian.

For the coupling coordinated degree $D$ between FDI and employment in these four districts, FDI system and employment system have been in benign coupling phase since year 2010 and in high level coupling phase since 2015. Beijing first opened its service industry first to the outside world as a pilot city in 2015. The opening further promoted the inflow of FDI to the four districts, especially to the general service sector and high-tech sector of these districts.

The order parameters of the two systems (Table 13) show that the development degree of the employment structure system is higher than that of the FDI system $\left(Z_{3}(y)>D_{3}(x)\right)$. The FDI system's parameter fluctuates greatly, indicating that the FDI system is not stable. The inflow of FDI in the near suburb requires to be further planned and guided, and a good external environment is needed to promote the inflow of FDI.

The sudden decrease in the order parameter of FDI system in 2015 may result in a sudden drop in $D$ value in 2015. The development of the FDI system was not stable, and the employment effect of FDI was not obvious; therefore, the employment effect of FDI still needs to be further improved.

From the order parameters of FDI and employment systems in the outer suburbs (Table 14), we can find that both the FDI system and employment system in four districts of outer suburb are at comparatively lower development phase compared with those of other areas in Beijing. There is a pseudo-coordination phenomenon between the two systems. The development of FDI system is relatively backward and unstable, and the interaction between FDI and employment is not significant. Therefore, the FDI inflows in the outer suburbs need to be 
Table 13. Coupling results between FDI and employment space-structure (Near Suburban Area).

\begin{tabular}{cccccccc}
\hline Year & $D_{3}(x)$ & $Z_{3}(y)$ & $C$ & $D$ & Type & Coupling phase \\
\hline 2006 & 0.0643 & 0.0100 & 0.0643 & 0.0254 & extreme inharmonious recession & low level coupling \\
2007 & 0.0608 & 0.1831 & 0.0608 & 0.1055 & severe inharmonious recession & low level coupling \\
2008 & 0.0659 & 0.3692 & 0.0659 & 0.1560 & severe inharmonious recession & low level coupling \\
2009 & 0.1094 & 0.4738 & 0.1094 & 0.2276 & moderate inharmonious recession & low level coupling \\
2010 & 0.1434 & 0.5664 & 0.1434 & 0.2850 & moderate inharmonious recession & low level coupling \\
2011 & 0.1070 & 0.7178 & 0.1070 & 0.2771 & moderate inharmonious recession & low level coupling \\
2012 & 0.6274 & 0.7809 & 0.6274 & 0.7000 & primary coordinated development & benign coupling \\
2013 & 0.4506 & 0.8237 & 0.4506 & 0.6092 & near-coordinated development & moderate coupling \\
2014 & 0.7403 & 0.8512 & 0.7403 & 0.7938 & moderate coordinated development & benign coupling \\
2015 & 0.1072 & 0.8541 & 0.1072 & 0.3026 & mild inharmonious recession & moderate coupling \\
2016 & 0.6804 & 0.7854 & 0.6804 & 0.7310 & moderate coordinated development & benign coupling \\
2017 & 0.6188 & 0.8866 & 0.6188 & 0.7407 & moderate coordinated development & benign coupling \\
\hline
\end{tabular}

Table 14. Coupling results between FDI and employment space-structure (Outer Suburb).

\begin{tabular}{ccccccc}
\hline Year & $D(x)$ & $Z(y)$ & $C$ & $D$ & Type & Coupling phase \\
\hline 2006 & 0.3859 & 0.2318 & 0.9684 & 0.5604 & near-coordinated development & moderate coupling \\
2007 & 0.3333 & 0.0989 & 0.8402 & 0.4486 & near-inharmonious recession & moderate coupling \\
2008 & 0.2894 & 0.3957 & 0.9879 & 0.5726 & near-coordinated development & moderate coupling \\
2009 & 0.2511 & 0.4456 & 0.9603 & 0.5620 & near-coordinated development & moderate coupling \\
2010 & 0.2554 & 0.6089 & 0.9125 & 0.6017 & primary coordinated development & benign coupling \\
2011 & 0.4650 & 0.5799 & 0.9939 & 0.7126 & moderate coordinated development & benign coupling \\
2012 & 0.4064 & 0.5403 & 0.9899 & 0.6748 & primary coordinated development & benign coupling \\
2013 & 1.0000 & 0.5304 & 0.9518 & 0.8792 & good coordinated development & benign coupling \\
2014 & 0.1798 & 0.6918 & 0.8092 & 0.5579 & near-coordinated development & moderate coupling \\
2015 & 0.0100 & 0.7208 & 0.2323 & 0.2615 & moderate inharmonious recession & low level coupling \\
2016 & 0.0884 & 0.6988 & 0.6316 & 0.4583 & near-inharmonious recession & moderate coupling \\
2017 & 0.1581 & 0.5829 & 0.8193 & 0.5184 & near-coordinated development & moderate coupling \\
\hline
\end{tabular}

further improved in terms of total volume, quality, spillover effects, and especially job creation effect, and it is advisable to create a favorable external environment to encourage and guide the FDI to promote the employment creation effect and knowledge spillover effect. The employment structure and wage level in the far suburbs must be further improved as well.

\section{Conclusions}

Based on Beijing city-level and district-level data and the concept of coupling 
from physics, we established a dual-system coupling model based on FDI and employment structure in Beijing to investigate the coupling mechanism and coupling effect between the two systems in terms of the sector structure, quality structure and spatial structure of employment. The results show that there is a certain coupling and interaction effect between FDI inflow and Beijing's sector structure of employment. FDI has a certain influence on Beijing's sector employment and sector wage, but its job creation effect and spillover effect still need to be further improved. The coupling coordinated degree between systems of FDI and employment quality-structure has been improved from the year 2008 to 2017, however, the quality structure of FDI and its employment effect needs to be further improved, which requires further guidance of FDI inflows. The coupling mechanism between the FDI system and employment space-structure system is not obvious, and the coupling coordinated degree differs across areas. Both FDI system and the employment space-structure system need to be further promoted. FDI inflows fluctuate greatly in the central urban areas, suburban areas and remote suburbs. The job creation effect and spillover effect of FDI are not obvious.

It is worth noting that the coupling effects between two systems in the near and outer suburbs are poor, and the development of the FDI system itself is unstable, indicating that FDI in these ten suburban districts need to be further regulated and refined in terms of its total inflow, industry distribution, job creation, and technology spillover.

As an important aspect of the industrial structure, employment structure reflects the real status of economic development and income distribution. In promoting the development of FDI and optimization of employment structure, we should pay special attention to several aspects: First, we should build a good external environment framework and rationally select FDI and guide FDI inflows into high-end services and newly emerging industries, and focus on promoting FDI's knowledge spillover effects; the second is to organize the spatial layout of FDI and rationally introduce FDI according to the resources endowment and developing patterns of each district. We should pay more attention to the job creation effect of FDI and the spatial layout of employment. The third is to focus on the cultivation of high-end talents, especially in the high-tech and high-end services sectors. The improvement of the employment quality-structure needs to be realized by knowledge-intensive employees. We can train high-end talents through various scientific research cooperation projects or introduce high-end talents through various channels.

\section{Supporting Projects}

1) The Coupling Mechanism between FDI and Employment Structure in Beijing, Beijing Municipal Education Commission Project (SM201510017001).

2) The Optimization of Beijing's Industrial Structure Based on SFDI, Beijing Social Science Foundation Project (13JGC072). 
3) The Employment Effects of Producer Services in Beijing, Beijing Municipal Education Commission Project (SM201610017001).

4) The Employment Support for Land-Expropriated Farmers of Daxing District in Beijing-from the Perspective of Three-dimensional Capital, Beijing Social Science Foundation Research Base Project (16JDSRC008).

5) Support Project of High-level Teachers in Beijing Municipal Universities in the Period of $13^{\text {th }}$ Five-year Plan.

\section{Conflicts of Interest}

The authors declare no conflicts of interest regarding the publication of this paper.

\section{References}

[1] Wen, H.D. and Tan, J.R. (2010) An Empirical Study of the Impact of China's Foreign Trade and FDI on Employment: Based on the Comparison of Eastern, Central and Western Data before and after WTO Entry. Journal of International Trade, 8, 102-109.

[2] Lipsey, R.E. and Sjöholm, F. (2001) Foreign Direct Investment and Wages in Indonesian Manufacturing. NBER Working Paper No. 8299.

https://doi.org/10.3386/w8299

[3] Borensztein, E., De Grgorio, J. and Lee, J.-W. (1998) How Does Foreign Direct Investment Affect Economic Growth? Journal of International Economics, 45, 115-135. https://doi.org/10.1016/S0022-1996(97)00033-0

[4] Yang, Y., Yu, Z.X. and Wang, M.J. (2009) Test of FDI's Employment Effect in China. The Economist, 5, 5-14.

[5] Liu, L.Y. (2011) FDI and Economic Development: Evidence from Mainland China. Journal of Service Science and Management, 4, 419-427. https://doi.org/10.4236/jssm.2011.44047

[6] Williams, D. (2003) Explaining Employment Changes in Foreign Manufacturing Investment in the UK. International Business Review, 12, 479-497. https://doi.org/10.1016/S0969-5931(03)00040-4

[7] Ding, C. and Guo, J.R. (2014) The Dynamic Effects and Regional Differences of Foreign Direct Investment Impact on Employment in China-GMM Estimation Based on Dynamic Panel Data Model. Economic Survey, 1, 33-45.

[8] Paniagua, J. and Sapena, J. (2014) Is FDI Doing Good? A Golden Rule for FDI Ethics. Journal of Business Research, 67, 807-812. https://doi.org/10.1016/j.jbusres.2013.11.049

[9] Zheng, Y.M. and Dong, D.X. (2008) Regional Differences and Dynamic Effects of Foreign Direct Investment on Employment in China-Based on Analysis of Dynamic Panel Data Model. Journal of Quantitative and Technical Economics, 5, 104-113.

[10] Cai, W. and Wang, D.W. (2004) Foreign Direct Investment and Employment: A Human Capital Analysis Framework. Collected Essays on Finance and Economics, 1, 1-14.

[11] Greenstone, M., Hornbeck, R. and Moretti, E. (2010) Identifying Agglomeration Spillovers: Evidence from Winners and Losers of Large Plant Openings. Journal of Political Economy, 118, 536-598. https://doi.org/10.1086/653714 
[12] Mao, R.S. (2009) Export, Foreign Direct Investment and China's FDI Employment. Economic Research Journal, 11, 105-117.

[13] Tang, D.B. (2011) The Impact of Globalization on China's Employment Structure. The Journal of World Economy, 9, 95-117.

[14] Olney, W.W. (2013) A Race to the Bottom? Employment Protection and Foreign Direct Investment. Journal of International Economics, 91, 191-203. https://doi.org/10.1016/j.jinteco.2013.08.003

[15] Liu, L.Y. (2012) FDI and Employment by Industry: A Co-Integration Study. Modern Economy, 3, 16-22. https://doi.org/10.4236/me.2012.31003

[16] Fu, X. (2011) Processing Trade, FDI and the Exports of Indigenous Firms: Firm-Level. Oxford Bulletin of Economics \& Statistics, 73, 792-817. https://doi.org/10.1111/j.1468-0084.2011.00673.x

[17] Todo, Y., Zhang, W.Y. and Zhou, L.-A. (2009) Knowledge Spillovers from FDI in China: The Role of Educated Labor in Multinational Enterprises. Journal of Asian Economics, 20, 626-639. https://doi.org/10.1016/j.asieco.2009.09.002

[18] Feenstra, R.C. and Hanson, G.H. (1997) Foreign Direct Investment and Relative Wages: Evidence from Mexico's Maquiladoras. Journal of International Economics, 42, 371-393. https://doi.org/10.1016/S0022-1996(96)01475-4 